\title{
ESPÉCIES CONGENÉRICAS DA MATA E DO CERRADO: TEOR DE PROTEÍNAS E COMPOSTOS FENÓLICOS
}

\author{
ELENICE MOURO VARANDA*, CARLA VALÉRIA RICCI** \\ \& IRME MAGNO BRASIL****
}

\footnotetext{
:Departamento Biologia, FFCLRP, Universidade de São Paulo. Av. Bandeirantes 3900. 14.040-901. Ribeirão Preto, SP, Brasil. e-mail: emvarand@spider.usp.br:

*:Departamento de Botânica, Instituto de Biociências, Universidade de São Paulo. C. Postal 11461, 05422-970 - São Paulo, SP, Brasil. *: :*: Bolsista de IC do $\mathrm{CNPq}$.
}

\begin{abstract}
Congeneric species from forest and cerrado: proteins and phenolics concentration). This paper deals with possible diferences in the control of phenylpropanoids biosynthesis in congeneric species from the forest and cerrado, through the quantification of foliar amount of phenols, lignins and proteins at the rainy and dry seasons. The results showed a tendency towards higher phenolic and lignin contents in the cerrado species and higher protein levels in the forest species wih some exceptions. The results agree partially with the initial hypothesis that the replacement of lost materials due to phytophagous attack is more expensive for vegetation which grows on poor soils than that on rich soils. Adaptative evolution results in modification of the biossynthetic apparatus, in this case the chiquimic acid pathway, in order to produce more defense compounds in cerrado plants. The results demonstrate a nced to analyse a greater number of species in order to investigate patterns at the level of families, genera, species or populations.

RESUMO - (Espécies congenéricas da mata e do cerrado: teor de proteínas e compostos fenólicos). Procurou-se verificar as possíveis variações no controle do acúmulo de fenilpropanóides comparativamente em espécies congenéricas de cerrado e de mata, nas estações seca c chuvosa. Para tanto foram analisados os teores de fenóis, ligninas e proteínas em folhas. Os resultaclos mostraram uma tendência a um maior acúmulo de compostos fenólicos e de ligninas nas espécies do cerrado e de proteínas nas espécies de mata com algumas exceções. Os resultados concordam em parte com a hipótese inicial de que a reposição dos materiais perdidos por ataque de fitófagos é mais dispendiosa para a vegetação que se desenvolve em solos pobres, havendo então um desvio da via biossintética, neste caso a via do ácido chiquímico, para a produção de compostos de defesa. Demonstraran que seria de interesse a análise de maior número de espécies a fim de se obter dados suficientes para a interpretação do comportamento em nível de famílias, gêneros, espécies ou populações.
\end{abstract}

Key words: phenols, proteins, lignins, cerrado and forest

\section{Introdução}

A vegetação de cerrado tem sido objeto de estudos de vários pesquisadores devido aos problemas ecológicos que suscita. Neste aspecto, foi dada ênfase inicial ao fator água até a década de 60 e, posteriormente, ao oligotrofismo dos solos (Goodland 1971) e às queimadas periódicas (Coutinho 1976).

Estudos envolvendo espécies intimamente relacionadas de mata e de cerrado que poderiam fornecer dados para a discussão da questão do aparccimento e evolução da vegetação do cerrado são escassos. Neste aspecto, podem ser salientados os trabalhos de Rizzini (1963) que apresentou uma lista de espécies vicariantes dos dois ambientes, de Válio et al. (1966 a, b) sobre balanço hídrico de Hymenaea stigonocarpa (cerrado) e H. stilbocarpa (mata), de Coutinho \& Pita (1971) que analisaram o teor de nutrientes do mesmo par de espécies c de Gottlieb et al. (1963) que verificaram, através de análise química, uma estreita relação entre Plathymenia foliolosa (mata) e $P$. reticulata (cerrado) e Dalbergia nigra (mata) e $D$. violacea (cerrado). Composições químicas muito próximas foram também constatadas entre Machaerium villosum (mata) e M. opacum (cerrado) e Kielmeyera excelsa (mata) e K. petiolares (cerrado) por Gottlieb et al. (1966).

Os estudos sobre a composição química têm avaliado apenas aspectos qualitativos, não mencionando as variações quantitativas. Neste trabalho pretendeu-se estudar em espécies congêneres de mata e de cerrado a relação entre o metabolismo fenólico e protéico através da análise dos teores de fenóis solúveis, ligninas e proteínas em folhas coletadas nas estações seca e chuvosa. Ao avaliar-se o equilíbrio entre a síntese protéica e fenólica nos dois ambientes pretendeu-se fornecer subsídios para uma melhor compreensão das relações ecológicas existentes no cerrado e examinar a aplicabilidade a hipótese de Janzen (1974) confirmada por 
Mckey (1978) em cluas florestas africanas, que estabelece que a vegetação que cresce $\mathrm{cm}$ solos pobres desenvolve uma maior concentração de compostos dissuasivos, por ser mais dispendiosa para estas planlats a reposição dos materiais perdidos pelo ataque de litólagos e da teoria de Coley et al. (1985) que propócm (jue a disponibilidade de recursos é a principal determinante da distribuição qualitativa e quantitativa de compostos de defesa.

\section{Material e Métodos}

Matterial Vegetal. Foram coletadas folhas adultas de 14 espécies relacionadas da mata e do cerrado pertencentes a fi famílias. As espécies de mata mesófila semidecídua foram coletadas na Fazenda Santa Carlota (21"23'S ( $47^{\prime \prime} 15 \mathrm{~W}$, alt. méclia $742 \mathrm{~m}$ ) no Município de Cajuru, SP', onde ocorrem cerrados, cerradões, matas ciliares e matas mesófilas semidecíduas, além de áreas de culturas temporárias e permanentes. As espécies de cerrado foram coletadas na Fazenda Canchim (Unidade de Execução de P'esquisa de Âmbito Estadual - UEPAE, orgão da EMBRAPA) no Município de São Carlos, SP (2 1"57'S c 47"5 l'W, alt. média 854m) que mantem uma rescerva deste tipo de vegetação.

Extraçăo e determinação do teor de fenóis solúveis totais. Três amostras de $\lg$ de folhas secas à sombra e pulverizadas, foram extraídas, segundo o método de Phillips \& Henshaw (1977), por três vezes, com $5 \mathrm{ml}$ de etanol $7(1 \%$ a auccidas cm banho-maria em tubos de centrífugal. Após centrifugação por $15 \mathrm{~min}$ (3000 rpm), os sobrenadantes foram recolhidos. O volume dos sobrenadantes reunidos foi completado para $5(0 \mathrm{ml}$. Da solução final, alíquotas de $0,1,0,2$ e $0,3 \mathrm{ml}$ adicionadas de (),5 $\mathrm{ml}$ de reagente de Folin-Denis, $1 \mathrm{ml}$ solução saturacla de $\mathrm{NaCO}_{3}$ e água destilada até completar o volume de $10 \mathrm{ml}$ foram submetidas a leitura $\mathrm{em}$ espectrofotômetro a $725 \mathrm{~nm}$, após uma hora (Swain \& Hillis 1959). Os dados de absorbância foram comparados aos de curva padrão construída a partir de soluçòes de concentrações crescentes de ácido gálico.

Dosagem de nitrogênio total e proteínas. $50 \mathrm{mg}$ de pó da amostra foram mineralizadas com selenito de sódio e mistura 1:1 de $\mathrm{CuSO}_{4}$ e Na, $\mathrm{SO}_{4}$ adicionados de $\mathrm{H}_{2} \mathrm{SO}_{4}$. Após a digestão, adicionou-se uma solução de $\mathrm{NaOH}$ e foi feita uma destilação. O destilado foi coletado em solução de $\mathrm{H}_{4} \mathrm{SO}_{4}(0,01 \mathrm{~N}$ de fator conhecido. O excesso de $\mathrm{H}_{2} \mathrm{SO}_{4}$ foì titulado com solução de $\mathrm{NaOH} 0,01 \mathrm{~N}$ (Horwitz 1980). O cálculo do teor protéico foi feito mulliplicando-se o valor percentual obtido para nitrosênio total pela constante 6,25 (Allen et al. 1972).
Dosagem de ligninas. Foi realizada pelo método A BCP M 10/71 do IPT, com adaptações para análise de material foliar (aumento do tempo de digestão com $\mathrm{H}_{22} \mathrm{SO}_{4}$ $72 \%$ de 2 para $4 \mathrm{~h}$ ). $1 \mathrm{~g}$ de folhas secas foi extraído com etanol $95 \%$ a quente por $4 \mathrm{~h}$. O material foi colocado em solução de etanol: benzeno (1:2) por 12h seguido de dois tratamentos de $30 \mathrm{~min}$ a frio com etanol $95 \%$ e fervido com $400 \mathrm{ml}$ de $\mathrm{H}_{42} \mathrm{O}$ destilada por $3 \mathrm{~h} \mathrm{em}$ banho-maria. Após lavagem com $100 \mathrm{ml}$ de água quente e $50 \mathrm{ml}$ de etanol $95 \%$ o resíduo foi seco ao ar, retomado com $15 \mathrm{ml} \mathrm{de} \mathrm{H}_{22} \mathrm{SO}_{4}$, resfriado até $13 \pm 2^{\prime \prime} \mathrm{C}$ e conservado a $19 \pm 1^{11} \mathrm{C}$ por 4 h. Após a digestão, o conteúdo foi transfericlo para erlenmeyer de 11 , adicionado de 560 $\mathrm{ml}$ de $\mathrm{H}_{22} \mathrm{O}$ destilada, fervido por $4 \mathrm{~h}$ e deixado em repouso. $O$ material foi filtrado através de papel previamente pesado, lavado com $500 \mathrm{ml}$ de $\mathrm{H}_{22} \mathrm{O}$ destilada e seco até peso constante, que corresponde às ligninas presentes na amostra.

Análise cstatística. Para a análise estatística foi aplicado o teste "U" de Mann-Whitney, não paramétrico (Siegel 1975) que é o mais indicado para grupos independentes com número de amostras diferentes. Fixou-se em $5 \%$ o nível para a rejeição da hipótese de nulidade.

\section{Resultados e Discussão}

$\mathrm{Na}$ estação chuvosa, a maioria das espécies de cerrado apresentaram maior teor de fenóis solúveis que as espécies congenéricas da mata, com exceção de Byrsonima verbascifolia e Qualea grandiflora (Tab. 1). Na estação seca, Xylopia aromatica e Byrsonima verbascifolia apresentaram teores de fenóis solúveis menores que as espécies congenéricas da mata. Esta última, de cerrado, apresentou teor de fenóis menor que $B$. coriacea, de mata, que por sua vez apresentou teor menor que outras duas espécies de cerrado analisadas, de mesmo gênero, tanto na estação seca como na chuvosa.

Os teores de protcínas da maioria das espécies de mata foi maior que de suas congenéricas de cerrado (Tab. 2). Porém, Xylopia aromatica apresentou teor de proteínas maior no cerrado $\mathrm{cm}$ ambas as estações, o mesmo ocorrendo com as espécies do gênero Rapanea. Para Vochysia e Qualea, encontrou-se maior teor protéico nas espécies de cerrado que nas de mata apenas na estação chuvosa.

Quanto às ligninas, todas as espécies de cerrado apresentaram maior teor que as espécies congenéricas da mata, na estação seca (Tab. 3). No entanto, na estação chuvosa, na maioria dos gêneros esta relação se inverte. Somentc B. coccolobifolia, Vochysia tucanorum e Aspiclosperma tomentosum apresentaram teores maiores de ligninas que as espécies congenéricas da mata. 
P’cla análise estatística aplicada aos resultados, verilïcamos que há diferenças significativas entre os dados obticlos para espécies de cerrado e de mata para fenóis totais, em ambas as estações e para ligninas na estação seca. Não se observaram diferenças significativas para os clados de proteínas e para ligninas na estação chuvosa. Não foram também encontradas diferenças significativas ao se comparar dados de cada um dos parâmetros analisados, obtidos nas diferentes estações ( $\mathrm{U}=25$ para fenóis/cerrado c mata; $\mathrm{U}=6 \mathfrak{6}$ para proteínas/mata; $\mathrm{U}=24$ para proteínas/cerrado; $\mathrm{U}=10$ para ligninas/mata; $\mathrm{U}=36$ para ligninas/cerrado)
Discutindo a relação entre a biossíntese de biopolímeros estruturais e metabólitos secundários na evolução dos vegetais, Gomes \& Gobllicb (1978) sugeriram que os primeiros desempenhariam importante papel na atribuição de aspectos morfológicos e os segundos na função biológica, sendo o equilíbrio entre ambos influenciado pelo ambiente. Assim, a via do ácido chiquímico, que leva à formação de fenilalanina, precursora tanto de proteínas como de fenilpropanóides, também pode ser afetada pelas condições ambientais (Gomes \& Gottlieb 1978). A formação de compostos fenólicos se dá pela desaminação de fenilalanina pela

Talsela 1. Teores de fenóis solúveis em porcentagem d., peso seco de folhas cle espécies congenéricas da mata e do cerrado.

\begin{tabular}{|c|c|c|c|c|c|}
\hline \multirow[b]{2}{*}{ mala } & \multirow[b]{2}{*}{ cerrado } & \multicolumn{2}{|c|}{ estação seca } & \multicolumn{2}{|c|}{ estação chuvosa } \\
\hline & & mata & cerrado & mata & cerrado \\
\hline Aspidespermüa cylindrocarpon Müll. Arg. & A. toncutosum Mart. & 3,32 & $*$ & 3,80 & 10,25 \\
\hline \multirow[t]{3}{*}{ Bytsonima aff. coriacea (L.) Kunth } & B.verbascifolia Rich. ex. A.Juss. & 4,12 & 3,70 & 3,16 & 2,65 \\
\hline & B. coccolobifolia H.B.K. & - & 6,03 & - & 6,03 \\
\hline & B.aff. intermedia A. Juss. & - & 5,91 & - & 11,10 \\
\hline Rapanca umbelata (Mart.) Mez & R. guianensis Aubl. & 5,72 & 5,87 & 2,97 & 5,71 \\
\hline Xylopia aromatica (Lam.) Mart. & X. aromatica (Lam.) Mart. & 5,97 & 3,75 & 4,36 & 4,98 \\
\hline Vochysia tucanortum Mart. & V. tucanorum Mart. & 1,55 & 1,77 & 1,12 & 2,27 \\
\hline Qualcajundiahy Warm. & Q. grandiflora Mart. & 4.37 & 6,03 & 6,00 & 5,50 \\
\hline Stylax sieberi Perk. & S. camporum Poln & * & 4,54 & 4,52 & 10,83 \\
\hline Mamm-Whitncy $(a=0,05 \%)$ & & \multicolumn{2}{|c|}{$\mathrm{U}=17$} & \multicolumn{2}{|c|}{$\mathrm{U}=15$} \\
\hline
\end{tabular}

* Espécic decídua

Tabela 2. Teores de proténas em porcentagem do peso seco de follas de espécies congenéricas da mata e do cerrado.

\begin{tabular}{|c|c|c|c|c|c|}
\hline \multirow[b]{2}{*}{ Mallal } & \multirow[b]{2}{*}{ cerraclo } & \multicolumn{2}{|c|}{ estação seca } & \multicolumn{2}{|c|}{ estação clıuvosa } \\
\hline & & matala & cerrado & Inata & cerraclo \\
\hline Aspiclosperman cylindrocarpon Müll. Args. & A. tomentosum Mart. & 8,37 & it & 8,37 & 10,62 \\
\hline \multirow[t]{3}{*}{ Bytsonimaaff. coriacca(L.) Kunth } & B. verlatscifolia Rich. ex. A. Juss. & $1.3,62$ & 7,31 & 18,37 & 8,87 \\
\hline & B. coccolobifolia H.B.K. & - & 9,45 & - & 5,75 \\
\hline & B.aff. imermedia A. Juss. & - & 10,31 & - & 10,12 \\
\hline Raypancal umbelata (Mart.) Mez & R. guianensis Aubl. & 6,81 & 9,75 & 4,37 & 8,75 \\
\hline Xylopia aromatica (Lam.) Mart. & X. aromatica (Lam.) Mart. & 4,37 & 12,75 & 8,70 & 14,05 \\
\hline Vochysia Incanortum Mart. & V. Iucanorum Nart. & 10,50 & 8,18 & 11,50 & 12,56 \\
\hline ()ualcajundiahyWarm. & Q. grandiflora Mart. & 9,62 & 7,87 & 8,37 & 10,31 \\
\hline Siylax sieberi Perk. & S. camportum Pohl & ; & 7,87 & $10, .31$ & 9,43 \\
\hline Mamm-Whituicy ( $a=0,05 \%)$ & & \multicolumn{2}{|c|}{$\mathrm{U}=24$} & \multicolumn{2}{|c|}{$\mathrm{U}=22$} \\
\hline
\end{tabular}

Tabela 3. Teores de ligninas em porcentagem do peso seco de folhas de espécies congenéricas da mata e do cerrado.

\begin{tabular}{|c|c|c|c|c|c|}
\hline \multirow[b]{2}{*}{ maltat } & \multirow[b]{2}{*}{ cerrado } & \multicolumn{2}{|c|}{ estação seca } & \multicolumn{2}{|c|}{ estação chuvosa } \\
\hline & & mata & cerrado & mata & cerrado \\
\hline Aspiclosperma cylindrocarpon Müll. Ary. & A. tomentosum Mart. & 16,31 & * & 15,91 & 24,49 \\
\hline \multirow[t]{3}{*}{ Byrsonima aff. coriacea (L.) Kunth } & B. verlaascifolia Rich. ex. A. Juss. & 22,06 & 23,38 & 25,60 & 19,23 \\
\hline & B. coccolobifolia H.B.K. & - & 24,91 & - & 25,84 \\
\hline & B. aff. intermedia A. Juss. & - & 25,34 & - & 23,21 \\
\hline Kapanca umbelata (Mart.) Mez & R. guianensis Aubl. & 22,71 & 25,44 & $25,4.3$ & $2.3,66$ \\
\hline Xylopia aromatica(Lam.) Mart. & X. anomatica (Lam.) Mart. & 25,23 & 30,81 & 30,90 & 29,27 \\
\hline Vochysia tucanortum Mart. & V. Ilucallortum Mart. & 13,27 & $23,4.3$ & 16,35 & 24,93 \\
\hline ()ualcal junclialıy Warm. & Q. grancliflora Mart. & 22,15 & 22,21 & 23,43 & 20,58 \\
\hline Siylas sielseril'erk. & S. camlpormun Polıl & * & 22,65 & 31,12 & 28,23 \\
\hline Mann-Whituey $(\mathrm{a}=0,05 \mathrm{~s} /(\mathrm{)})$ & & \multicolumn{2}{|c|}{$\mathrm{U}=7$} & \multicolumn{2}{|c|}{$\mathrm{U}=3.3$} \\
\hline
\end{tabular}

* Espécie decíclua 
PAL (fenilalanina-amônia-liase) resultando em ácido cinâmico e, durante a evolução dos vegetais terrestres, os derivados de ácido cinâmico que, de início, eram precursores de lignina, passaram a precursores de compostos fenólicos de função dissuasiva através da co-evolução com bactérias, fungos, insetos, pássaros e mamíleros, resultando numa diminuição no porte dos vegetais (Gomes \& Gottlieb 1978). Observa-se deste modo, uma maior ocorrência de fenóis em plantas arbórcas atuais, especialmente nas das subclasses Dilleniiclac, Hamamelidae e Rosidae (sensu Cronquist, 1981), $\mathrm{com}$ tendência à perda destes compostos e substituição por outros compostos de defesa na transição Rosidae-Asteridae (Gardner 1977 apud Godoy et al. 1997).

Margna (1977) salientou que o controle da biossíntese de compostos fenólicos depende do suprimento do substrato, ou seja, em última análise, de fenilalanina e $\mathrm{NH}_{3}$, que determinam o equilíbrio entre síntese protéical é de fenilpropanóides. Deste modo, condições que favorecem a síntese protéica levam à diminuição do acúmulo de fenilpropanóides. Por outro lado, aquelas que suprimem a síntese protéica ou aumentam a velocidade de degradação catabólica de proteínas estimulam a biossíntese de fenilpropanóides. Phillips \& Henshaw (1977) observaram esta mesma regulação cm Acer pseudoplatanus L. , através de cultura de células em suspensão.

Janzen (1974) elaborou a hipótese de que o maior acúmulo de compostos dissuasivos em vegetação que se desenvolve em solos pobres é devido à reposição de materiais ser mais dispendiosa nesta que naquelas que se estabelecem em solos ricos. McKey et al. (1978) confirmaram tal hipótese analisando folhas de espécies arbóreas de florestas tropicais estabelecidas $\mathrm{cm}$ solos de areias ácidas que apresentaram quase o dobro da concentração de compostos fenólicos que as estabelecidas em solos lateríticos.

Colcy (1986), discutindo a defesa por taninos, salientou a dificuldade de se avaliar os benelícios da mesma e que são raros os trabalhos que quantificam simultaneamente custos e benefícios de defesas. Em seus estudos com Cecropia peltata, concluiu que a produção de taninos, que é benéfica em termos de proteção contra a herbivoria, estava associada a um custo que resul$10 u \mathrm{em}$ redução na produção de folhas.

Colcy ct al. (1985) propondo a teoria da alocação de recursos, consideraram que a disponibilidade de recursos é a principal determinante tanto da quantidade como da qualidade das defesas químicas. Postularam que o investimento em defesas é maior, em plantas com baixa taxa de crescimento e que possuem folhas mais duradouras, quando comparadas às plantas de crescimento rápido, pois a seleção natural favorece as primciras $\mathrm{cm}$ ambientes com baixa disponibilidade de recursos. Salatino (1993), em trabalho sobre a relação entre o escleromorfismo oligotrófico das plantas de cerrado e o investimento em defesas químicas, discutiu as várias teorias de ecologia química. Considerou a teoria de Coley et al. (1985) a mais adequada para a interpretação da maior freqüência de esclerofilia e de taninos e menor ocorrência de outras classes de compostos, como defesas nitrogenadas, em espécies de cerrado quando comparadas com espécies de mata.

As espécies de cerrado normalmente apresentam folhas escleromorfas devido ao grande acúmulo de lignina em tecidos esclerenquimáticos. A importância evolutiva da lignina, derivada biossintética do ácido cinâmico (Gomes \& Gottlieb, 1978) é inquestionável. Sua importância na proteção das plantas contra o ataque de patógenos (Friend 1976 apud Swain 1979) e de herbívoros tem sido salientada pelos ecologistas por tornar, os tecidos onde se acumula, indigeríveis, impalatáveis e pouco atrativos (Swain 1979). O efeito deletério sobre a disponibilidade de proteínas e carbohidratos foi demonstrado em Locusta migratoria alimentada com Sorghum bicolor (Woodhead \& Cooper-Driver 1979 apud Swain 1979). Swain (1979) afirma que as ligninas e os taninos, estes últimos também comuns em plantas do cerrado (Salatino 1993), são os mais importantes componentes dos vegetais, não só por sua distribuição quase universal mas também pela sua história, mais antiga que qualquer outra classe de compostos secundários. Tais compostos têm merecido a atenção dos pesquisadores nas últimas décadas. Zucker (1983), em interessante revisão sobre taninos, ressalta sua importância ecológica, questionando o conceito de que tais compostos são gerais e inespecíficos em suas interações com herbívoros e patógenos formando complexos com proteínas. Considera os taninos como substâncias de funções variadas devido ao seu enorme potencial para estereoespecificidade. Propõe relacionar a estrutura dos diferentes tipos de taninos e a função de defesa que possa exercer.

Pelos dados apresentados no presente trabalho conclui-se que a hipótese proposta por Janzen (1974) pode ser aplicada a alguns pares de espécies analisadas como, por exemplo, no par congenérico Byrsonima coriacea (mata) x B. coccolobifolia (cerrado). Em Vochysia, a mesma espécie, $V$. tucanorum, foi analisada nos dois ambientes e somente os dados de proteínas, na estação chuvosa representou exceção à hipótese de Janzen (1974). Os dados obtidos para as espécies de Qualea na estação seca, concordam com esta hipótese, mas não para os obtidos na estação chuvosa. Por outro lado, Xylopia aromatica analisada nos dois ambientes mostrou comportamento bem diverso, com a maioria dos dados não concordando com a hipótese proposta. No gênero Rapanea o maior teor de fenóis solúveis na es- 
pécies de cerrado não foi acompanhado de menores valores de proteínas e os valores de lignina não apresentaram diferenças muito grandes entre os dois ambientes.

Aspiclosperma tomentosum do cerrado e Styrax sieberi de mata são espécies decíduas na estação seca, o que difícultou comparações mais conclusivas a respeito do comportamento nestes gêneros em relação a biossíntese cle fenóis, proteínas e ligninas.

Pela análise de 22 espécies de Leguminosae, 11 de cerrado e 11 de mata mesófita, Salatino (1993) observou maior acúmulo de fenóis em detrimento de proteínas nas espécies de cerrado, porém não observou diferença significativa entre os níveis de ligninas das espécies dos dois ambientes.

A hipótese de Coley et al. (1985), segundo Salatino (1993), reforça a teoria do escleromorfismo oligotrófico, permitindo uma interpretação de seu significado ecológico em habitats nutricionalmente estressado como é o caso do cerrado. Pelos nossos resultados, não se pode afirmar que o acúmulo maior de compostos fenólicos em detrimento de um acúmulo protéico em plantas cle cerrado seja um comportamento geral, uma vez que na maioria dos casos, baixos teores de fenóis não corresponderam a altos teores protéicos.

Assim, parece-nos razoável admitir uma segunda hipótese: a tendência do desvio da via do ácido chiquímico em espécies que se desenvolvem em solos de cerrado em relação a espécies de mesma família e/ou gênero que crescem em solos mais ricos não é uma estratégia comum a todos os táxons. A disponibilidade de fenilalanina parece levar à biossíntese tanto de fenóis como de proteínas, variando o desvio da via para um ou outro, dependendo do táxon considerado, ou este desvio leva à síntese de ligninas e não de fenóis solúveis.

Deste modo pode-se afirmar que a análise deve ser aplicada não só à vegetação como um todo mas também a cada família individualmente para uma conclusão mais segura da medida da influência do ambiente sobre a via do ácido chiquímico. Ainda, acreditamos que um maior número de indivíduos de cada espécie deva ser analisado, com maior número de coletas de daclos, incluindo a análise de outros parâmetros entre cles o grau de esclerofilia, a duração das folhas e a velocidade de crescimento, a fim de se acompanhar a variação biossintética no decorrer de todo o ano.

\section{Agradecimentos}

As autoras agradecem à FAPESP e ao CNPq pelo apoio financeiro, à Dra Lázara Cordeiro do Departamento de Botância do Instituto de Biociências da UNESP-Rio Claro pelas dosalgens de nitrogênio, a Dra. Maria Helena Antunes de Oliveira e Souza do Departa- mento de Botânica da UFSCar pela identificação das espécies de cerrado a João Augusto Meira Neto e Luiz Bernacci pela identificação das espécies de mata e a José Ricardo Barosela pelo apoio técnico.

\section{Referências}

ALLEN, S. E., GRIMSHAW, H. M., PARKINSON, J. A. \& QUARMBY, C. 1972. Chemical Analysis of Ecological Materials. Blackwell Scientific Publications. Oxford.

COLEY, P. D. 1986. Costs and benefits of defense by tamnins in a neotropical tree. Oecologia 70: 238-241.

COLEY, P. D., BRYANT, J. P. \& CHAPIN, F. S. 1985. Resource availability and plant antiherbivore defense. Science 230 (4728): 895899.

COUTINHO, L. M. 1976. Contribuição ao conhecimento do papel ecológico das queimadas na floração de espécies de cerrado. Tese de LivreDocência. Instituto de Biociências, Universidade de São Paulo. São Paulo.

COUTINHO, L. M. \& PITA, S. M. 1971. Estudo comparativo do teor de alguns nutrientes minerais em sementes de duas espécies vicariantes de jatobá (Hymenaea stignocarpa Mart. e H. stilbocarpa Hayne). Revista Brasil. Biol. 31 (3): 357-360.

CRONQUIST, A. 1981. An Integrated System of Classification of Flowering Plants. Columbia University Press. New York.

GODOY, S. A. P., MAYWORM, M. A. S. , LO, V. K., SALATINO, A. \& SCHAEFFER-NOVELLI, Y. 1997. Teores de ligninas, nitrogênio e taninos em folhas de espécies típicas do mangue. Revista Brasil. Bot. 20(1): 35-40.

GOMES, C. \& GOTTLIEB, O. R. 1978. The evolution of structural biopolymers and secondary metabolites is comnected? Revista Brasil. Bot. 1: 41-45.

GOODLAND, R. J. A. 1971. Oligotrofismo e alumínio no cerrado. In M.G. Ferri (coord.) III Simpósio sobre o Cerrado. EDUSP e Edgard Blucher: São Paulo, p. 44-60.

GOTTLIEB, O. R., TAVEIRA-MAGALHÃES, M. \& MORS, W. B. 1963. Problemas e possibilidades da fitoquímica no cerrado. In M.G. Ferri (coord.) Simpósio sobre o Cerrado. EDUSP. São Paulo, p. 227-283.

GOTTLIEB, O. R., MEDITSH, J. O. \& TAVEIRA-MAGALHÃES, M. 1966. Com vistas ao aproveitamento do cerrado como ambiente natural: composição química de espécies arbóreas. An Acad. Brasil. Ciênc. 38 (Supl.): 303-314.

HORWITZ, W. (ed) 1980. Official methods of analysis of the Association Chemists. ed. 13. Association Off.Agr. Chemists. Menasha.

JANZEN, D. H. 1974. Tropical blackwater rivers, animals, and mast fruiting by the Dipterocarpaceae. Biotropica 6(2): 69-103.

MARGNA, U. 1977. Control at the level of substrate supply. An alternative in the regulation of phenylporpanoid accumulation in plant cells. Phytochemistry 16: 419-426.

MCKEY, K., WATERMAN, P. G., GARTLAN, J. S. \& STRUHSABER, T. T. 1978. Phenolic content of vegetation of two African rain forests: ecological implications. Science 202 (4363): 61-64.

PHILLIPS, R. \& HENSHAW, G. G. 1977. The regulation of synthesis of phenolics in stationary phase cell cultures of Acer pseudoplatanus L. J. Exp. Bot. 28 (105): 785-794.

RIZZINI, C. T. 1963. A flora do cerrado In M.G. Ferri (coord.) Sintpósio sobre o Cerrado. Reimp. 1971. Edgard Blücher. São Paulo, p. $105-145$.

SALATINO, A. 1993. Chemical ecology and the Theory of Oligitrophic Scleromorphism. An. Acad. Brasil. Ciênc. 65 (1): 1-13.

SIEGEL, S. 1975. Estatística não-paramétrica para Ciências do Comportamento. Trad. A. A. de Farias. MacGraw Hill do Brasil. 
SWAIN, T. 1979. Tamnins and lignins. In G.A. Rosenthal \& D.H. Jaurzen (eds.) Herbivores - their-Interaction with Scondauy Metabolites. Acaclemic P'ress. New York, p. 657-681.

SWA IN, T. \& HILLIS, N. E. 1959. The phenolic constituents of Prumus clomestica. I - The quantitative analysis of phenolic constitucult.s. J. Sci. Agric. 10): 63-68.

VÁLIO, I. F. M., MORAES, V. H., MARQUES, M. \& CAVALCANTLE, I'. B. 1966a. Estudo comparativo do balanço d'água de Hymenaca stignocarpa Mart e de Hymenaca stilbocarpa Hayne em condições de cerrado na estação seca. An. Acald. Brasil. Ciênc. 38 (supl.): 261-276.

VÁLIO, I. F. M., MORAES, V., MARQUES, M., MATOS. M. E. R. \& de PAULA, J. E. 1966b. Estudo comparativo do balanço d'água de Iymenaea stignocarpa Mart e de Hymenaea stilbocarpa Hayne em condições de cerrado na estação chuvosa. An. Acacl. Brasil. Ciênc. 38 (supl.): 291-302.

ZUCKER. W. V. 1983. Tannins: does structure determine function? An ecological perspective. Am. Nat. 121: 335-365. 